\title{
Prototype Development for the Periodontal Model System with the Spatial Compartmentalization by the Additive Manufacturing
}

\author{
Chan Ho Park ${ }^{1,2}$ (D) \\ 1 Department of Dental Biomaterials, School of Dentistry, Kyungpook National University, Daegu 41940, \\ Korea; chanho@knu.ac.kr; Tel.: +82-53-660-6890 \\ 2 Institute for Biomaterials Research and Development, Kyungpook National University, Daegu 41940, Korea
}

Received: 16 October 2019; Accepted: 1 November 2019; Published: 4 November 2019

\begin{abstract}
At present, various tissue engineering strategies have been developed for multiple tissue regeneration and integrative structure formations. However, the regenerations of tooth-supportive structures are still limited and challenging due to the micro-interfacial compartmentalization of multiple tissues, their integrations for systematic responses, and spatiotemporal organizations of engineered tissues. Here, we investigated the scaffold prototype as the regeneration platform of the periodontal complex (cementum-periodontal ligament (PDL)-bone). Based on the tooth image dataset, the prototype scaffold was designed with individual periodontal tissues while using the

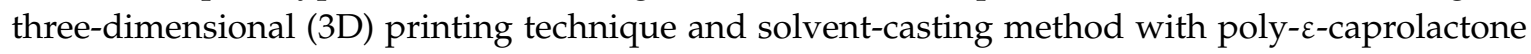
(PCL). The architecture was characterized by scanning electron microscope (SEM) and biological assessments were performed with human periodontal ligament (hPDL) cells by confocal microscope. In particular, the angulations and deformations of hPDL cells on PDL architectures were analyzed while using nuclear aspect ratio $(\mathrm{NAR}=2.319 \pm 0.273)$ and nuclear shape index (NSI (circularity) $=0.546 \pm 0.0273$ ). In in-vitro, designed surface microgroove patterns facilitated angular organizations of hPDL cells (frequency of $0-10^{\circ}$ angulations $=75 \pm 9.54$ out of $97.3 \pm 2.52$ ) for seven days. The prototype scaffolding system showed geometric adaptation to the digitized image dataset, hPDL orientations on microgroove-patterned surface, and architectural compartmentalizations for periodontal tissue regeneration.
\end{abstract}

Keywords: 3D printing; periodontal tissues; biopolymer; tissue engineering; CAD

\section{Introduction}

Periodontia or periodontal tissues have typically spatial compartmentalization for different tissue types, like cementum (the mineralized layer on tooth-root surface), periodontal ligament (PDL; fibrous connective tissues with perpendicular orientations to tooth-root surface), alveolar bone (the mineralized structures to support tooth constructs), and gingiva (the soft tissue structure to protect tooth-surrounding tissues as a barrier) [1]. In particular, the tooth-supporting (or periodontal) complex is the hierarchical architecture, like cementum-PDL-bone with strong tissue integrations by Sharpey's fibers, which are the terminal ends of principal fibers to facilitate PDL bundle insertions into the mineralized tissue surfaces like cementum and bone surface [2-4]. Of various tooth-supportive functions in the periodontal complex, PDL requires spatiotemporal orientations and angular configurations to mainly generate biomechanical responses under mastication loadings [2,5].

Periodontitis or periodontal disease is the inflammatory chronic disease to induce the destructions of tooth-supporting structures and increase serious tooth mobility, including tooth root exposures, which can produce sensory responses or pains from the dental pulp [6-8]. Some severe cases require 
tooth extractions and place dental prosthetics, like dental implants or dentures to replace functioning of natural teeth. However, dental implants, which are directly placed into regenerated bone tissues or bone substitutes after bone healing within the tooth-extraction socket have recently reported about peri-implantitis, lost stability of implants, sensory limitations, or biomechanical malfunctioning [9-11]. Therefore, periodontal tissue constructs and their systemic integrations are significantly required to support and preserve natural teeth [3,4,12].

Various spatiotemporal scaffolding systems have been recently developed and applied for tissue replacement or regeneration. Many different types of scaffolding systems have been developed for multi-tissue and interface formations [4,9,13-15], but, to date, these approaches still have limitations in complete tissue integration, their functional restorations, and regenerated tissue-controllable architecture designs. After culturing PDL cells on thermosensitive culture dishes, engineered PDL cell sheets facilitated to promote periodontal tissue regeneration like cementum, PDL, and alveolar bone around the periodontal defects in the canine model [16]. The strategy could be beneficial without artificial biomaterials in transplanting biologics, but it was limited to 3D organize fibrous connective tissues with specific angulations, which would be the main factor in restoring periodontal functions and generating appropriate biomechanical responses against mastication loadings [16,17]. To overcome the difficulties, computer design-based fabrication techniques, such as rapid prototyping and solid freeform fabrication methods, can permit the design of desired and predictable geometric structures to regulate multiple tissue formations $[5,13]$. Up to recently, Park et al. investigated fiber-guiding biopolymeric scaffolds for alveolar bone and PDL (bone-PDL scaffold) regenerations while using the additive manufacturing system in mandibular fenestration defects of the rodent model $[15,18]$. In addition, the selective laser sintering (SLS) system created the designed biopolymeric scaffold with the remarkable architectural adaptability to the disease-induced geometric defect [14]. In addition, soft lithographic strategies are currently utilized to investigate optimal designs with sub-micron level topographic architecture for the perpendicular PDL guidance $[19,20]$. The freeze-casting method could create 3D longitudinal pore structures as the PDL-guidable architectures and control the pore directionalities for the structural similarity to natural PDL orientations [5]. Recently, the rough surfaces by the solvent-casting method while using the biopolymer solution and the micropatterned surface, which reinterpreted stair-stepping errors of the additive manufacturing, were created in order to attach, proliferate, and orient PDL cells for seven and 21 days in in-vitro [21]. Although many different approaches have been developed for bone-PDL complex regenerations surrounding tooth structures, it could be the other critical challenge in designing and developing the 3D platform for the bone-PDL-cementum complex formation to reflect individual tooth topographies or specific tooth-surface features. In particular, the cementogenesis plays a key integrative role to anchor PDL fibrous bundles to tooth-root dentin surface, but it is limited to create the platforms with the compartmentalization as a cementum scaffold in the engineered periodontal complex (or hybrid periodontal scaffold system) [22]. Various spatiotemporal scaffolding systems have more concentrated on promoting alveolar bone regeneration and PDL formation with specific orientations because many researchers have still believed that the cementum regeneration strongly depends on physiological responses generated by PDLs or biomechanical microenvironments under mastication or occlusion, [2]. Moreover, it is a major challenge to regulate the optimal dimension formations without ankylosis, the bone fusion to the tooth-root surfaces and develop the highly-predictable techniques for periodontal complex neogeneses [2,4].

Here, the advanced periodontal complex prototype was designed with the cementum platform with the previous bone-PDL, fiber-guiding scaffold [15], and it was manufactured by the three-dimensional (3D) wax printing system. Based on the image dataset of micro-computed tomography (micro-CT) scanned extracted tooth, cementum platform was computer-designed with $200-\mu \mathrm{m}$ thickness between PDL-guiding architectures and the tooth-root surface. In addition to the dimensional compartmentalization for individual periodontal tissues, like cementum, PDL, and alveolar bone, 
microgroove patterns on the PDL-guiding architecture surface were created for perpendicularly angular organizations of cells to the tooth-root surface.

\section{Materials and Methods}

\subsection{The Tooth Image Dataset Generation with a STL File Format}

The fourth pre-molar or the first molar teeth of the maxilla of the canine model were extracted and soft tissues around teeth were removed while using proteinase $\mathrm{K}$ (Sigma-Aldrich, St. Louis, MO, USA) after rinsing the extracted. The cleaned teeth were placed in the hydroperoxide $\left(\mathrm{H}_{2} \mathrm{O}_{2}\right)$ and cementum layers were removed using the dental curette. To generate the STL file format of treated teeth, the micro-computed tomography (micro-CT; Skyscan 1172, Bruker-microCT, Knotich, Belgium) was utilized with $11.55 \mu \mathrm{m}^{3}$ voxel size under a $40 \mathrm{kV}$ source voltage and a $200 \mu \mathrm{A}$ source current. After 3D rendering, the files were saved as a STL file format and bad triangles, which were generated during converting CT data to STL image datasets, were fixed using the software Netfabb (Autodesk, San Rafael, CA, USA).

\subsection{Design and Manufacture of the Prototype of a Perio-Complex Scaffold}

Based on the fixed STL image dataset of the tooth, perio-complex scaffolds were designed with cementum platform, PDL-guiding architectures, and bone region in a single construct while using the computer-design program, Solidworks 2018 software (Dassault System SOLIDWORKS Corp., Waltham, MA, USA). The layer thickness was set to $25.40 \mu \mathrm{m}$ in the slicing process to create microgroove patterns during additive manufacturing (Figure 1) [21]. After manufacturing wax molds by the 3D wax printer

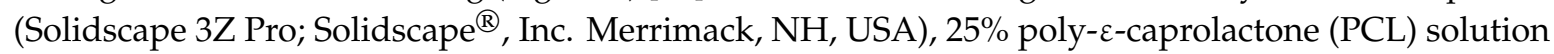
in 1,4-dioxane was freeze-casted with prepared wax molds (Figure 2). The 1,4-dioxane was extracted using $99 \%$ ethanol at $-20^{\circ} \mathrm{C}$ for 2-3 days and at $4{ }^{\circ} \mathrm{C}$ for 2-3 days, and then the wax molds (red support wax; Solidscape ${ }^{\circledR}$, Inc. Merrimack, NH, USA) was dissolved in cyclohexane at $35-37^{\circ} \mathrm{C}$ for $1-2$ days. After removing red wax materials, $99 \%$ ethanol was utilized to remove cyclohexane solvent and the PCL scaffolds were stored in $70 \%$ ethanol at $4{ }^{\circ} \mathrm{C}$ until the in-vitro experiments [21].

\subsection{In-Vitro Experiments and Assessments of Cell Orientations and Morphologies}

The human periodontal ligament (hPDL) cells were cultured in passage 4-6 with minimum essential medium alpha ( $\alpha$-MEM), including $10 \%$ fetal bovine serum (FBS) and antibiotics (100 units/mL penicillin). $1 \times 103 \mathrm{hPDL}$ cells were seeded into the scaffolds and incubated for seven days. To determine cell orientations and morphologies, cell nucleus staining with DAPI (4', 6 -diamidino-2-phenylindole, Life Technologies (Thermo Fischer Scientific, Waltham, MA, USA) and F-actin staining with phalloidin (Alexa Fluoro ${ }^{\circledR} 546$ Phalloidin, Life Technologies, Carlsbad, CA, USA) after fixing cells. ImageJ software (National Institutes of Health; NIH, Bethesda, MD, USA) was utilized to measure the nuclear aspect ratio (NAR), nuclear shape index (NSI; circularity), and nuclear orientations to the reference direction $[21,23]$.

\subsection{Statistical Analysis}

All the data were statistically analyzed while using the mean \pm standard deviation. The in-vitro experiments were performed with three different scaffolds $(n=3)$.

\section{Results}

The prototyped scaffold adapted a single root shape of the 4th premolar tooth (P4) or the first molar tooth (M1), which were extracted from the mandible (for M1) or the maxilla (P3) of the canine model. After scanning the extracted tooth and generating STL file format by the micro-CT, the image dataset was utilized to design a geometrically adaptable platform for the cementum layer (Figure 1). After shrinking the tooth STL file to form the $25-\mu \mathrm{m}$ difference, which could be represented as the 
cementogenesis platform (Figure 1). Based on the layer, 250- $\mu \mathrm{m}$ PDL architectures were designed with the perpendicular directions to the cementum layer and bone scaffold was created with the track-structure, which osteogenic biologics could be loaded in (Figure 1). After slicing the design scaffold, the 3D wax printing system manufactured the sacrificial wax molds to cast polymeric materials.

\section{CT-scanned Extracted Tooth}

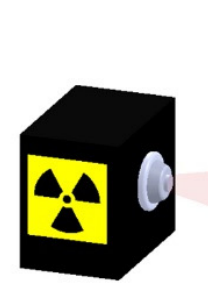

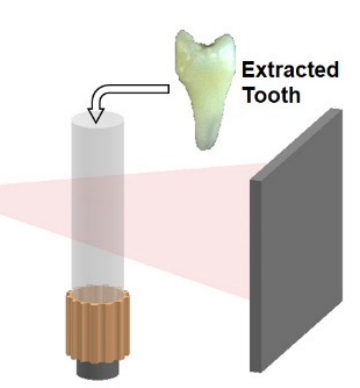

Scaffold Design using Tooth Image Dataset

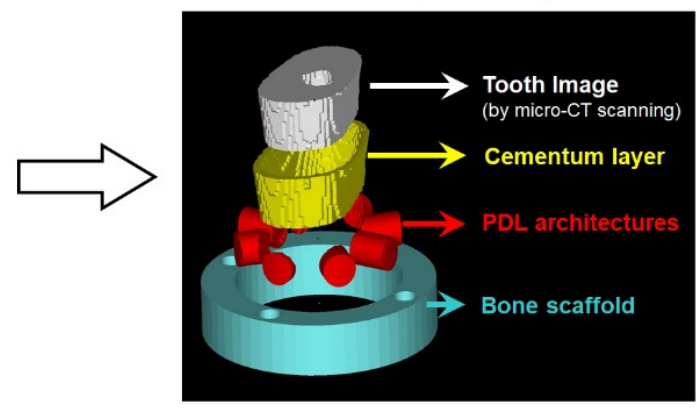

\section{D-reconstructed} Tooth Image

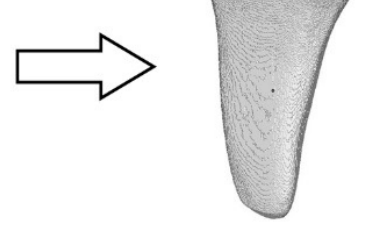

\section{STL-converted Image Dataset}

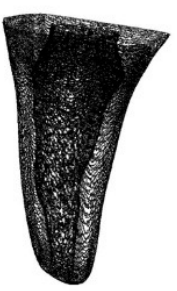

Figure 1. The additive manufacturing process to produce wax molds for the prototype of the periodontal model system. After the micro-computed tomographic (micro-CT) scanning of extracted teeth, the three-dimensional (3D) image was reconstructed and generated as a STL file format. Based on the image dataset, the scaffold prototype was designed with the compartmentalization for cementum (yellow-colored), periodontal ligament (PDL; red-colored), and alveolar bone (blue-colored). The three different compartmentalized parts were assembled and the scaffold prototype was sliced, the 3D wax printer manufactured sacrificial wax molds.

The polymeric material, poly- $\varepsilon$-caprolactone (PCL) was dissolved in 1,4-dioxane solvent with $25 \%$, which was based on various previous studies [20]. The building wax material (blue wax) was removed by $100 \%$ ethanol and remaining supporting material (red wax) molds were utilized to cast $25 \%$ PCL solution (Figure 2). After freeze-drying the 25\% PCL-mold, excessive PCL materials were trimmed and sacrificial red wax materials were dissolved with cyclohexane to obtain PCL scaffolds (Figure 2).

The PDL scaffolds were perpendicularly arranged to the cementum layer with the parallel microgrooves to the directions of PDL architectures. In particular, the stair-stepping errors, which were formed during the additive manufacturing in wax molds, could be substituted to the microgrooves on PDL scaffold surfaces by freeze-casting with $25 \%$ PCL solution (Figure 3). As the previous study demonstrated [21], microgroove patterns with the 25- $\mu \mathrm{m}$ intervals could control PDL cell orientations as well as promote the cell adhesion on pattern surfaces, which had the roughness that was derived from the solvent casting with the 25\% PCL solution (Figure 3). 
3-D Printed Wax Mold

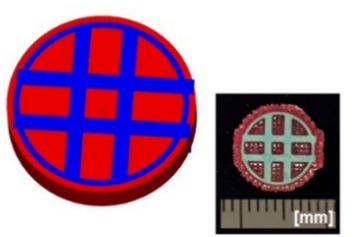

Removing Build Material

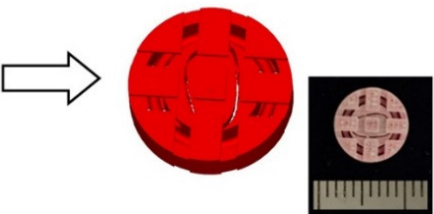

Casting PCL Material

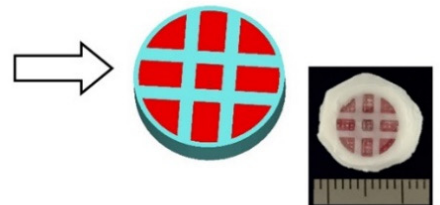

Freeze-casting PCL Material
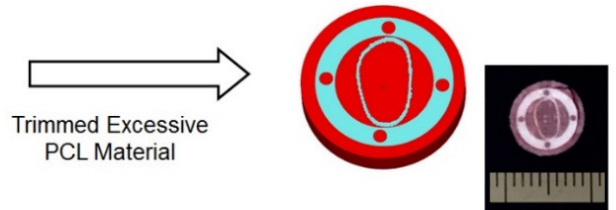

Removing Support Material
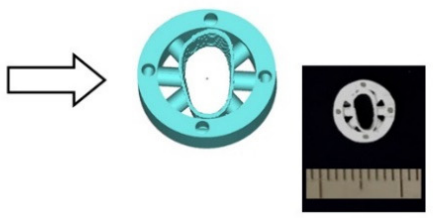

Figure 2. The flow scheme to produce the prototype scaffolding system with polymeric material, poly- $\varepsilon$-caprolactone (PCL). After removing the blue wax material (build wax) by ethanol, 25\% PCL in 1,4-dioxane solution was casted and frozen for the freeze-drying process. Excessive PCL materials around the red wax mold (support wax) were trimmed and cyclohexane was utilized to completely dissolve red wax materials to obtain the PCL scaffolds.
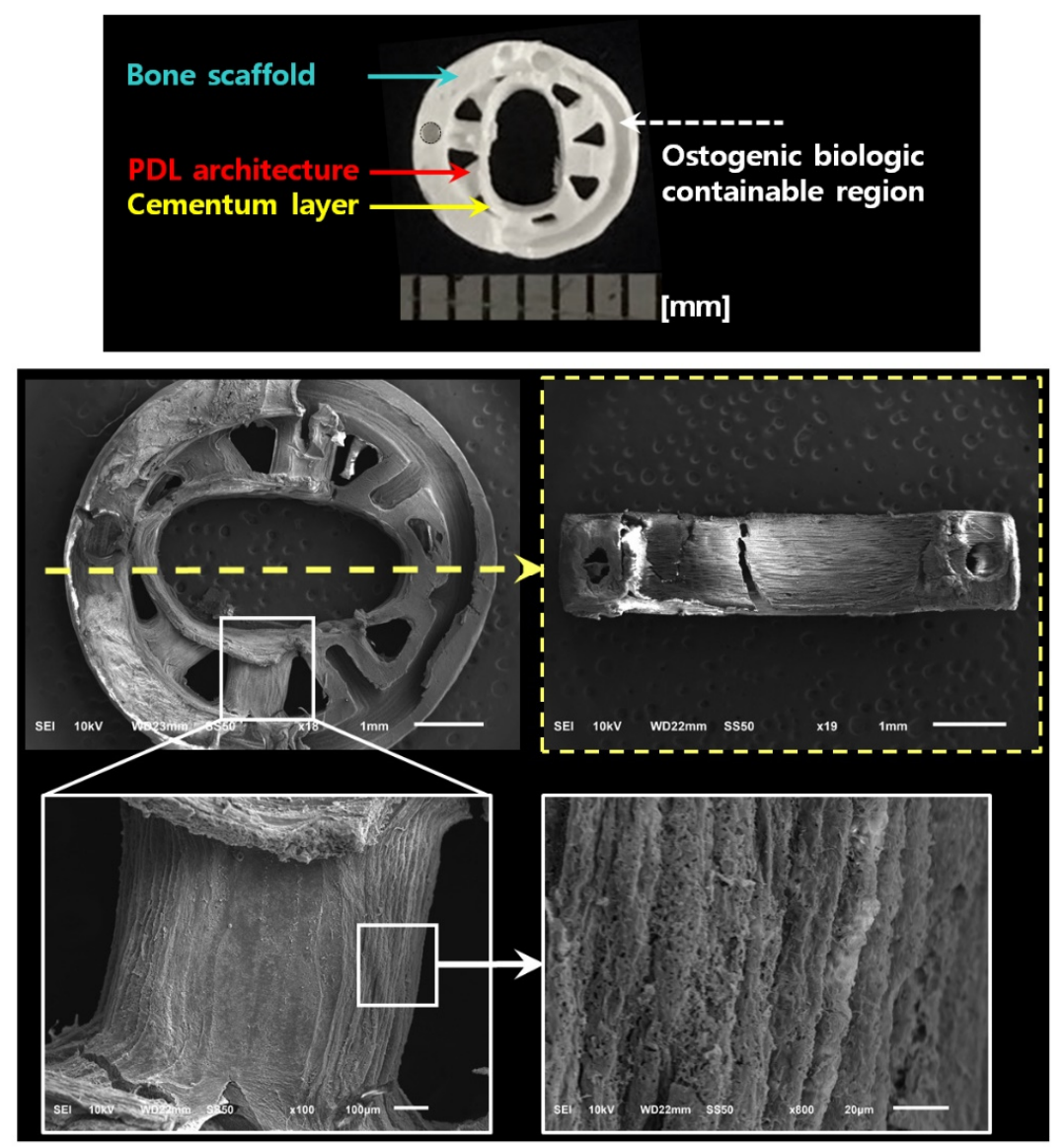

Figure 3. The optical image of the cross-sectioned scaffold and scanning electron microscope (SEM) images for morphological characteristics. In the bone scaffold part, the biologic-loadable tack was observed and approximately 250- $\mu \mathrm{m}$ PDL architectures showed the perpendicular directions to the cementogenesis platform and $25-\mu \mathrm{m}$ interval microgroove patterns on the surface as well as the surface roughness. 
After seeding and culturing $1.0 \times 103$ human PDL (hPDL) cells per scaffold for seven days, the fluorescence-staining was performed to analyze deformations and angulations of cell nucleus as well as qualitatively assess cytoskeletal structures by organized F-actin bundles (Figure 4). Although the top surface of PDL architectures was relatively smoother than the side surface with microgroove patterns (Figure 3), the hPDL cells had parallel organization, which could be influenced with aligned hPDL cells following microgroove-patterned surfaces (Figure 4). Cell shapes and cell orientations were assessed while using three different parameters; nuclease aspect ratio (NAR), nuclear shape index (NSI), and nuclear angles $[21,23]$. The NAR was calculated with the long-to-short axis ratio of DAPI-stained nuclei (NAR $=$ long axis/short axis $=2.319 \pm 0.273$ (mean \pm standard deviation); Figure 4 ) and NSI showed low nuclear circularity after identification between zero for linear and one for circular shape $(\mathrm{NSI}=0.546 \pm 0.0273$; Figure 4$)$. Based on the reference direction, which was determined by the microgroove patterns, the frequency of nuclear angulations (or the number of nuclei) in angular range $0-10^{\circ}$ to the reference was calculated and then analyzed with $75 \pm 9.54$ out of total number of nuclei $(97.3 \pm 2.52)$ in three different scaffolds (Figure 4).
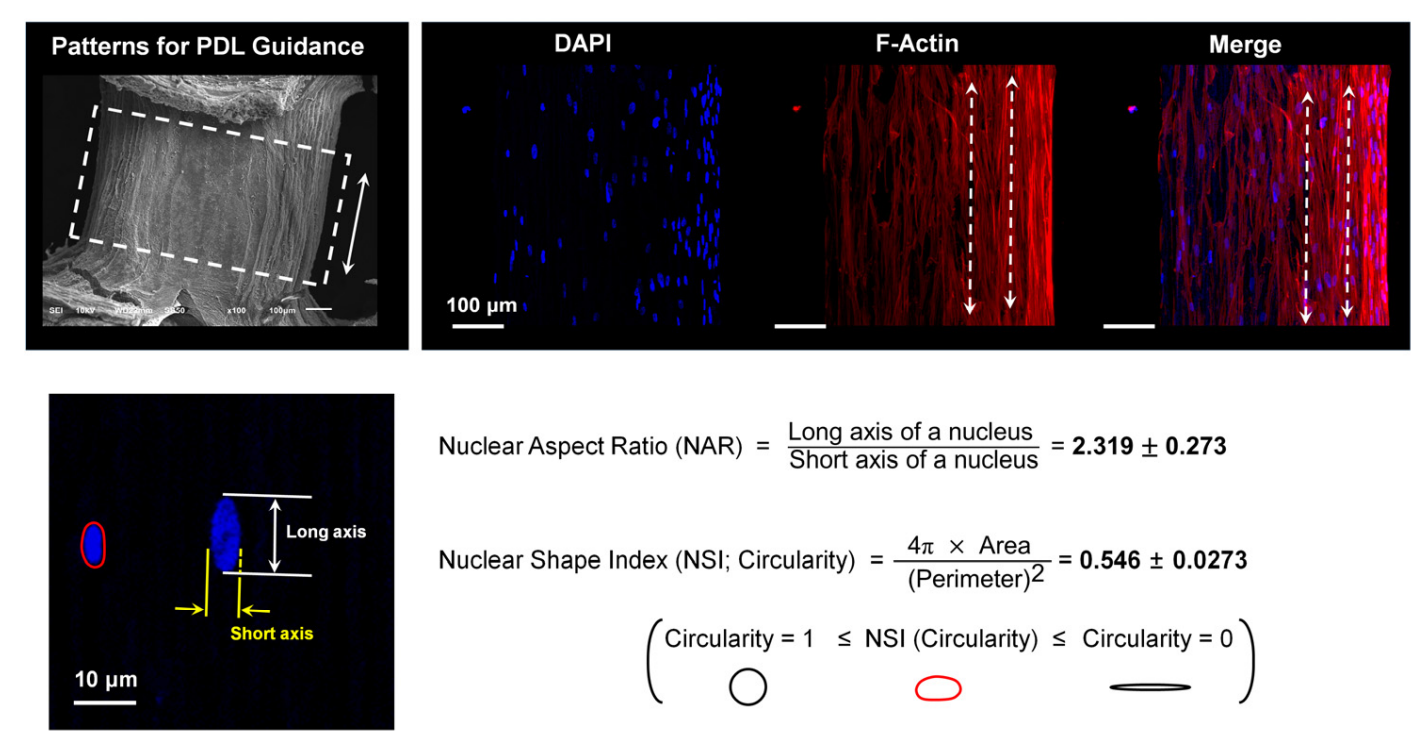

Nuclear Shape Index (NSI; Circularity) $=\frac{4 \pi \times \text { Area }}{(\text { Perimeter })^{2}}=0.546 \pm 0.0273$
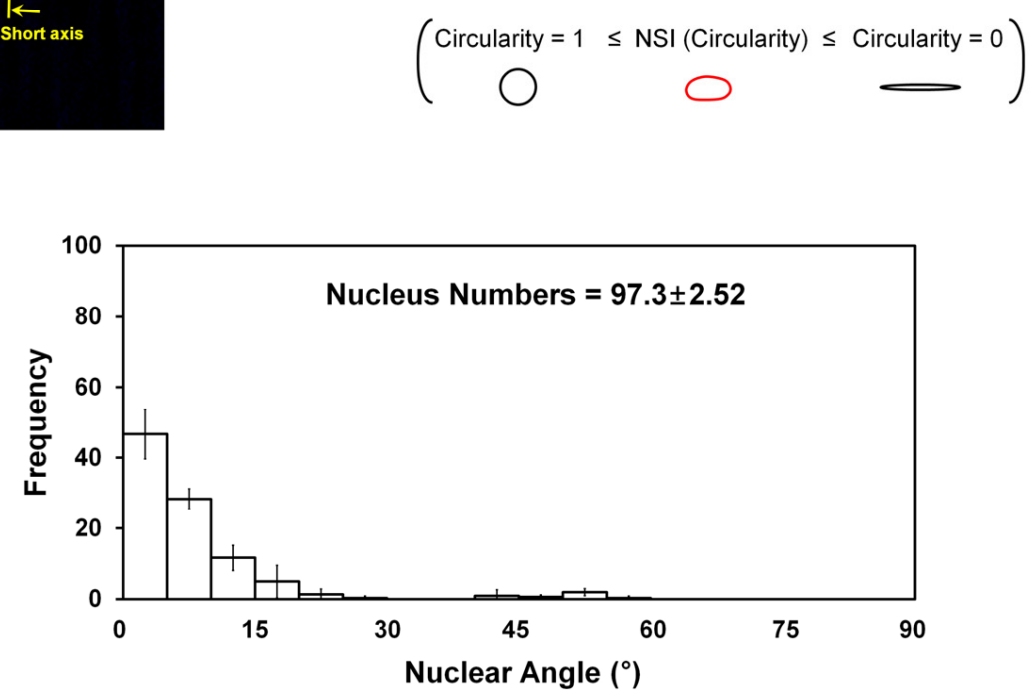

Figure 4. Fluorescence staining for qualitative and quantitative assessments of cell orientation and nuclear deformations on PDL-guiding architectures. Cell nuclei were stained using 4',6-diamidino-2-phenylindole (DAPI) and F-actin filaments were stained using phalloidin to determine cell orientations by nuclear angulations and cell shapes by nuclear deformation (nuclear aspect ratio; NAR and nuclear shape index (circularity); NSI). NAR could be characterized as NAR = 1 for the same of both axes. The nuclear angulations were measured with the statistics and $77 \%$ of nuclei was angulated within $0-10^{\circ}(\mathrm{n}=3)$. 


\section{Discussion}

Various engineering approaches have been recently developed for periodontal tissue regenerations, such as the bone formation to support teeth or dental implants, the PDL regeneration with provision of approximately $250-\mu \mathrm{m}$ interface or perpendicular/oblique angular orientations to tooth-root surfaces, or biologic deliveries to promote bone and cementum formation [21]. The bone formation has been investigated while using highly porous scaffolding systems loading with osteogenic-differentiation factors, like BMPs, PDGF, or other proteins [24,25]. In particular, PDL regeneration with angular organizations for tooth-supportive functioning restorations have been studied with 3D platform design strategies, like the freeze-casting method [5], 3D printing system [21], soft-lithographic approaches [19], or PDL cell sheet engineering [26]. Although there have been many different types of scaffolding systems for individual periodontal tissue neogeneses, it is typically limited to develop a single structure to provide spatial compartmentalizations for cementum, PDL, and alveolar bone. In particular, the cementum is a significant tissue for facilitating the anchorage of fibrous connective tissues on tooth-root surface. However, many studies have still demonstrated the cementogenesis could be activated while using transmitted stimulations by mastication loadings and PDL should be the major component to contribute cementum formation avoiding the ankylosis, which makes the direct fusion between tooth-root surface and bone surface $[4,18,22,27]$.

For individual tissue formations within a single system, the prototype of perio-complex scaffolding system was developed while using the image dataset, which was generated using the micro-CT scanned, extracted tooth (Figure 1). The SEM images showed the cementum layer, which was reflected with the designed thickness $(25.40 \mu \mathrm{m})$ and microgroove patterns on the surface of PDL-guiding architectures with the roughness, which could be created by the solvent casting method with $25 \%$ PCL solution (Figure 2) [21]. According to the qualitative analysis using SEM, the cementum layer (or cementogenesis platform) could have spatially dimensional similarity to natural cementum tissue on the tooth-root surface. In particular, the additive manufacturing (3D printing) system can provide the reproducibility of microgroove patterns on PDL structure surfaces, so the topological features to moderate cell alignments were highly predictable and controllable (Figure 4). In addition to the analysis of nuclear angulations corresponding to cell orientations, nuclear deformation measurements using nuclear aspect ratio (NAR) and nuclear shape index (NSI; circularity) were performed, because NAR $(2.319 \pm 0.273)$ and NSI $(0.546 \pm 0.0273)$ could provide critical information to define cell collectivity regulations while using cytoskeletal orientations and cell angulations when the cell populations increased or strong cell-to-cell integrations [21,23]. Based on anisotropic morphologies of cell nuclei (Figure 4), collective cell responses and cytoskeletal organizations could be determined as the previous study mentioned [21,23].

Various studies reported that the single cell angulation analysis on various 2D or 3D substrates with topological properties has been analyzed while using F-actin formations, alignments, or distributions in cytoskeletal structures $[23,28]$. Accordingly, a single cell membrane or cytoskeletal actin filaments could be the part to qualitatively and quantitatively determine the cell shapes and morphological characteristics $[23,29]$. However, when the cells are formed as groups with diverse intercellular junctions, it is difficult to analyze cell orientations or angulations while using individual cell shapes or morphological directions [21]. Versaevel et al. demonstrated that the morphological changes of cells or cell collectiveness are critically related with nuclear shapes to regulate gene expressions in cytoskeletons and they could be the biomechanical responses to spatial microenvironments [23]. Based on this study, topological fabrications of substrates or scaffolds have been demonstrated to re-organize tissue or cells and form engineered tissues with structural similarities to the natural tissues, such as aligned ligaments or porous bone [30]. In particular, cellular morphology and shapes could be one of significant parameters to determine tissue morphogenesis with structural characteristics [23]. The morphological changes of cells are critically related with nuclear shapes to regulate gene expressions in cytoskeletons and they could be the biomechanical responses to spatial microenvironments [23,31]. Therefore, nuclear deformations and orientations could be an essential factor to reflect cytoskeletal 
rearrangements for cell shapes or tissue-like cell collectivity organizations with the calculations of cell nuclear angulations and deformation while using NSI (or circularity) and NAR, respectively [21].

Although this study mainly concentrated on the design and manufacture of the perio-complex scaffold using the 3D printing technique, the prototype for biological and physiological functions is required to have more porous interiors of scaffolds, which could facilitate cemetum-like tissue formation with dimensional specificity. To create architectural differentiation with different porosities for the cementogenesis platform, the solvent-casting method incorporated with the submicron-scaled porogen-leaching technique or the lower concentrated PCL solution casting method could be potentially considered. The optimization of scaffold manufacturing technologies for perio-complex scaffolds would not be the major issue because various conventional scaffolding systems have been investigated to improve cell activities, like attachment, proliferation, or differentiation [15,32,33], or tissue regeneration with regulations of tissue ingrowth [34-36]. Rather, a compartmentalized scaffolding system with micron-scaled interfaces, like the cementum layer, PDL architectures with cell-/tissue-guiding micro-patterns, and bone regeneration parts, was challenging for the spatial regulations of three different periodontal tissues.

In pre-clinical and clinical situations, the PCL scaffold has been widely developed for various tissue regenerations with successfully clinical uses with the approval of U.S. Food and Drug Administration (US-FDA). In particular, the 3D printing technology represents a promising approach for providing personalized architectures to overcome clinical diversities. However, it is still challenging for periodontal complex tissue (cementum-PDL-bone) neogeneses with the 3D printing systems due to the complicated geometric and anatomical specificities for multiple tissue classifications with micro-scales. Therefore, the proposed prototype could provide compartmentalized hybrid constructs and spatiotemporally controllable platforms for cemetogenesis, PDL orientations, and bone formation, which are required for periodontal functioning restorations as tooth-supportive structures. The perio-complex scaffolding system can be accessibly extended to more clinically relevant models with predictable and controllable clinical treatments for periodontal tissue regenerations.

\section{Conclusions}

After the sacrificial wax molds were manufactured by the 3D printing technique, the solvent-casting method using $25 \%$ PCL solution created the single prototype scaffold having rough surface to promote cell adhesion and 3D printer-generated microgroove patterns to guide cell orientations in in-vitro environment with the perpendicular directions to the cementum layer or the tooth-root surface. In conclusion, the study demonstrated that the prototype scaffolding system can be designed with (1) geometric adaptation of extracted teeth to generate the cementogenesis platform, (2) perpendicular directionality of PDL architectures to the cementum layer, (3) microgroove patterns on PDL-guiding architectures to angularly organize fibrous cells, and (4) bone regeneration structures around the PDL structures. Although the cementogenesis platform should be modified for high porosity and in-vivo studies are required, the prototype design for three different tissues in a single system could provide architectural potential for spatial compartmentalization of the tissue complex (cementum-PDL-bone).

Author Contributions: C.H.P. designed/manufactured the prototypes of perio-complex scaffolds, performed in-vitro experiments, analyzed data, and wrote the manuscript.

Funding: The study was supported by Osteology Foundation (\#16-173) in Switzerland and National Research Foundation of Korea (NRF-2016R1D1A1B03935686).

Acknowledgments: The author thanks Yang-Jo Seol (Department of Periodontology, School of Dentistry, Seoul National University, Seoul, South Korea) for kindly providing the human periodontal ligament (hPDL) cell line.

Conflicts of Interest: The author declares no conflict of interest. 


\section{References}

1. Menicanin, D.; Hynes, K.; Han, J.; Gronthos, S.; Bartold, P.M. Cementum and Periodontal Ligament Regeneration. Adv. Exp. Med. Biol. 2015, 881, 207-236.

2. Park, C.H. Biomaterial-Based Approaches for Regeneration of Periodontal Ligament and Cementum Using 3D Platforms. Int. J. Mol. Sci. 2019, 20, 4364. [CrossRef]

3. Park, C.H.; Kim, K.H.; Lee, Y.M.; Seol, Y.J. Advanced Engineering Strategies for Periodontal Complex Regeneration. Materials 2016, 9, 57. [CrossRef]

4. Kim, J.H.; Park, C.H.; Perez, R.A.; Lee, H.Y.; Jang, J.H.; Lee, H.H.; Wall, I.B.; Shi, S.; Kim, H.W. Advanced biomatrix designs for regenerative therapy of periodontal tissues. J. Dent. Res. 2014, 93, 1203-1211. [CrossRef]

5. Park, C.H.; Kim, K.H.; Rios, H.F.; Lee, Y.M.; Giannobile, W.V.; Seol, Y.J. Spatiotemporally controlled microchannels of periodontal mimic scaffolds. J. Dent. Res. 2014, 93, 1304-1312. [CrossRef]

6. Rajeshwari, H.R.; Dhamecha, D.; Jagwani, S.; Rao, M.; Jadhav, K.; Shaikh, S.; Puzhankara, L.; Jalalpure, S. Local drug delivery systems in the management of periodontitis: A scientific review. J. Control. Release 2019, 307, 393-409.

7. Liu, J.; Ruan, J.; Weir, M.D.; Ren, K.; Schneider, A.; Wang, P.; Oates, T.W.; Chang, X.; Xu, H.H.K. Periodontal Bone-Ligament-Cementum Regeneration via Scaffolds and Stem Cells. Cells 2019, 8, 537. [CrossRef]

8. Pihlstrom, B.L.; Michalowicz, B.S.; Johnson, N.W. Periodontal diseases. Lancet 2005, 366, $1809-1820$. [CrossRef]

9. Larsson, L.; Decker, A.M.; Nibali, L.; Pilipchuk, S.P.; Berglundh, T.; Giannobile, W.V. Regenerative Medicine for Periodontal and Peri-implant Diseases. J. Dent. Res. 2016, 95, 255-266. [CrossRef]

10. Laster, Z.; Weissberg, I.; Kablan, F. Biomechanics and peri-implantitis: The effect of a subcrestal wing-thread to decrease alveolar crestal bone strain. theory, finite element analysis, and clinical application. Int J. Oral Maxillofac. Implants 2014, 29, e265-e271. [CrossRef]

11. Mathieu, V.; Vayron, R.; Richard, G.; Lambert, G.; Naili, S.; Meningaud, J.P.; Haiat, G. Biomechanical determinants of the stability of dental implants: Influence of the bone-implant interface properties. J. Biomech. 2014, 47, 3-13. [CrossRef] [PubMed]

12. Xu, X.Y.; Li, X.; Wang, J.; He, X.T.; Sun, H.H.; Chen, F.M. Concise Review: Periodontal Tissue Regeneration Using Stem Cells: Strategies and Translational Considerations. Stem Cells Transl. Med. 2019, 8, $392-403$. [CrossRef] [PubMed]

13. Vaquette, C.; Pilipchuk, S.P.; Bartold, P.M.; Hutmacher, D.W.; Giannobile, W.V.; Ivanovski, S. Tissue Engineered Constructs for Periodontal Regeneration: Current Status and Future Perspectives. Adv. Healthc. Mater. 2018, 7, 1800457. [CrossRef] [PubMed]

14. Rasperini, G.; Pilipchuk, S.P.; Flanagan, C.L.; Park, C.H.; Pagni, G.; Hollister, S.J.; Giannobile, W.V. 3D-printed Bioresorbable Scaffold for Periodontal Repair. J. Dent. Res. 2015, 94, 153-157. [CrossRef] [PubMed]

15. Park, C.H.; Rios, H.F.; Jin, Q.; Sugai, J.V.; Padial-Molina, M.; Taut, A.D.; Flanagan, C.L.; Hollister, S.J.; Giannobile, W.V. Tissue engineering bone-ligament complexes using fiber-guiding scaffolds. Biomaterials 2012, 33, 137-145. [CrossRef] [PubMed]

16. Tsumanuma, Y.; Iwata, T.; Washio, K.; Yoshida, T.; Yamada, A.; Takagi, R.; Ohno, T.; Lin, K.; Yamato, M.; Ishikawa, I.; et al. Comparison of different tissue-derived stem cell sheets for periodontal regeneration in a canine 1-wall defect model. Biomaterials 2011, 32, 5819-5825. [CrossRef]

17. Takahashi, H.; Nakayama, M.; Itoga, K.; Yamato, M.; Okano, T. Micropatterned thermoresponsive polymer brush surfaces for fabricating cell sheets with well-controlled orientational structures. Biomacromolecules 2011, 12, 1414-1418. [CrossRef]

18. Park, C.H.; Rios, H.F.; Taut, A.D.; Padial-Molina, M.; Flanagan, C.L.; Pilipchuk, S.P.; Hollister, S.J.; Giannobile, W.V. Image-based, fiber guiding scaffolds: A platform for regenerating tissue interfaces. Tissue Eng. Part C Methods 2014, 20, 533-542. [CrossRef]

19. Pilipchuk, S.P.; Fretwurst, T.; Yu, N.; Larsson, L.; Kavanagh, N.M.; Asa'ad, F.; Cheng, K.C.K.; Lahann, J.; Giannobile, W.V. Micropatterned Scaffolds with Immobilized Growth Factor Genes Regenerate Bone and Periodontal Ligament-Like Tissues. Adv. Healthc. Mater. 2018, 7, 1800750. [CrossRef]

20. Pilipchuk, S.P.; Monje, A.; Jiao, Y.; Hao, J.; Kruger, L.; Flanagan, C.L.; Hollister, S.J.; Giannobile, W.V. Integration of 3D Printed and Micropatterned Polycaprolactone Scaffolds for Guidance of Oriented Collagenous Tissue Formation In Vivo. Adv. Healthc. Mater. 2016, 5, 676-687. [CrossRef] 
21. Park, C.H.; Kim, K.H.; Lee, Y.M.; Giannobile, W.V.; Seol, Y.J. 3D Printed, Microgroove Pattern-Driven Generation of Oriented Ligamentous Architectures. Int. J. Mol. Sci. 2017, 18, 1927. [CrossRef] [PubMed]

22. Park, C.H.; Oh, J.H.; Jung, H.M.; Choi, Y.; Rahman, S.U.; Kim, S.; Kim, T.I.; Shin, H.I.; Lee, Y.S.; Yu, F.H.; et al. Effects of the incorporation of epsilon-aminocaproic acid/chitosan particles to fibrin on cementoblast differentiation and cementum regeneration. Acta Biomater. 2017, 61, 134-143. [CrossRef] [PubMed]

23. Versaevel, M.; Grevesse, T.; Gabriele, S. Spatial coordination between cell and nuclear shape within micropatterned endothelial cells. Nat. Commun. 2012, 3, 671. [CrossRef] [PubMed]

24. Dang, M.; Saunders, L.; Niu, X.; Fan, Y.; Ma, P.X. Biomimetic delivery of signals for bone tissue engineering. Bone Res. 2018, 6, 1-12. [CrossRef] [PubMed]

25. De Witte, T.M.; Fratila-Apachitei, L.E.; Zadpoor, A.A.; Peppas, N.A. Bone tissue engineering via growth factor delivery: From scaffolds to complex matrices. Regen. Biomater. 2018, 5, 197-211. [CrossRef] [PubMed]

26. Onizuka, S.; Iwata, T. Application of Periodontal Ligament-Derived Multipotent Mesenchymal Stromal Cell Sheets for Periodontal Regeneration. Int. J. Mol. Sci. 2019, 20, 2796. [CrossRef]

27. Bosshardt, D.D. Are cementoblasts a subpopulation of osteoblasts or a unique phenotype. J. Dent. Res. 2005, 84, 390-406. [CrossRef]

28. Ahmed, W.W.; Wolfram, T.; Goldyn, A.M.; Bruellhoff, K.; Rioja, B.A.; Moller, M.; Spatz, J.P.; Saif, T.A.; Groll, J.; Kemkemer, R. Myoblast morphology and organization on biochemically micro-patterned hydrogel coatings under cyclic mechanical strain. Biomaterials 2010, 31, 250-258. [CrossRef]

29. Keren, K.; Pincus, Z.; Allen, G.M.; Barnhart, E.L.; Marriott, G.; Mogilner, A.; Theriot, J.A. Mechanism of shape determination in motile cells. Nature 2008, 453, 475-480. [CrossRef]

30. Chen, F.M.; Liu, X. Advancing biomaterials of human origin for tissue engineering. Prog. Polym. Sci. 2016, 53, 86-168. [CrossRef]

31. Ron, A.; Azeloglu, E.U.; Calizo, R.C.; Hu, M.; Bhattacharya, S.; Chen, Y.; Jayaraman, G.; Lee, S.; Neves-Zaph, S.R.; Li, H.; et al. Cell shape information is transduced through tension-independent mechanisms. Nat. Commun. 2017, 8, 2145. [CrossRef] [PubMed]

32. Thadavirul, N.; Pavasant, P.; Supaphol, P. Development of polycaprolactone porous scaffolds by combining solvent casting, particulate leaching, and polymer leaching techniques for bone tissue engineering. J. Biomed. Mater. Res. A 2014, 102, 3379-3392. [CrossRef] [PubMed]

33. Hou, Q.; Grijpma, D.W.; Feijen, J. Preparation of interconnected highly porous polymeric structures by a replication and freeze-drying process. J. Biomed. Mater. Res. B Appl. Biomater. 2003, 67, 732-740. [CrossRef] [PubMed]

34. Pan, Z.; Ding, J. Poly (lactide-co-glycolide) porous scaffolds for tissue engineering and regenerative medicine. Interface Focus 2012, 2, 366-377. [CrossRef]

35. Tan, Q.; Li, S.; Ren, J.; Chen, C. Fabrication of porous scaffolds with a controllable microstructure and mechanical properties by porogen fusion technique. Int. J. Mol. Sci. 2011, 12, 890-904. [CrossRef]

36. Huang, A.; Jiang, Y.; Napiwocki, B.; Mi, H.; Peng, X.; Turng, L.S. Fabrication of poly ( $\varepsilon$-caprolactone) tissue engineering scaffolds with fibrillated and interconnected pores utilizing microcellular injection molding and polymer leaching. RSC Adv. 2017, 7, 43432-43444. [CrossRef]

(C) 2019 by the author. Licensee MDPI, Basel, Switzerland. This article is an open access article distributed under the terms and conditions of the Creative Commons Attribution (CC BY) license (http://creativecommons.org/licenses/by/4.0/). 